\title{
Generalization gradients following training on a symbolic matching-to-sample task
}

\author{
ROBIN L. BOWERS and RALPH W. RICHARDS \\ Colorado State University, Fort Collins, Colorado
}

\begin{abstract}
The major finding in the present experiment was that line orientation controlled pigeons' responding after training on a one-key symbolic matching-to-sample task. When the vertical line appeared as the sample, testing along the line dimension produced incremental and decremental generalization gradients, depending on the color of the comparison. Conversely, when the vertical line served as the comparison, incremental and decremental gradients also emerged, but here the type of gradient depended on the color of the sample. Thus, both the color of the sample (comparison) and line orientation exerted control of behavior.
\end{abstract}

Stimulus control of operant behavior occurs if the value of an antecedent stimulus determines the probability with which the operant is emitted. Using the refined methodology of Guttman and Kalish (1956), numerous researchers (see reviews by Honig \& Urcuioli, 1981; Rilling, 1977; Terrace, 1966) have employed the shape and slope of empirical generalization gradients to examine dimensional stimulus control (cf. Hearst, Besley, \& Farthing, 1970; Honig, Boneau, Burstein, \& Pennypacker, 1963; Thomas, 1970, 1985). For example, Honig et al. (1963) trained two groups of pigeons on a simple discrimination in which the key was successively illuminated by a black vertical line on a white background or by a plain white light. In one group, the vertical line was associated with reinforcement and the blank key was associated with extinction. During the generalization test, subjects' responding to the line decreased in an orderly fashion as the line progressively tilted away from vertical. In the second group, the line was associated with extinction and the blank key was associated with reinforcement. Here an orderly increase in responding occurred as the line was tilted away from vertical.

In a more recent study, Richards (1979) employed a within-subjects design and again obtained decremental and incremental generalization gradients along the lineorientation dimension. In Richards's study pigeons were trained on a more complex conditional discrimination, in which pecks to a vertical line or blank key were either reinforced or not reinforced depending on the simultaneous presence of other stimuli. More specifically, for some subjects, pecking during the vertical line was reinforced when the chamber and line's background were red, but was not reinforced when the chamber and background

The authors would like to thank the anonymous reviewers for their helpful comments toward improving the quality of this paper. Portions of these data were presented at the 1985 meeting of the Rocky Mountain Psychological Association in Tucson, Arizona. Reprints may be obtained from Bill Richards, Department of Psychology, Colorado State University, Fort Collins, CO 80523. were white. However, pecking to the blank key was reinforced during white but not during red. When the various line orientations were combined with red, a decremental generalization gradient was obtained, and when combined with white, an incremental generalization gradient was obtained. Richards's findings were theoretically important in that the results challenged the theoretical view, which states that when a task places high demand on a subject's processing system, irrelevant features, such as a line's orientation, will not exert control of responding (for further discussion, see Sutherland \& Mackintosh, 1971).

The purpose of the present study was to further examine whether task difficulty determined whether irrelevant features established control, but, unlike Richards's study, the present study examined stimulus control after training on a symbolic matching-to-sample task. Matching-to-sample has been used extensively as a tool for investigating cognitive processes in animals (see Carter \& Werner, 1978; Farthing, Wagner, Gilmour, \& Waxman, 1977; Honig, 1978, 1984; Maki \& Leith, 1973; Riley, Cook, \& Lamb, 1981; Roberts \& Grant, 1978). During a typical matching-to-sample trial, a sample is presented on the center key of a three-key panel and then, perhaps after some delay, two comparison stimuli are presented on the side keys. The animal obtains reward by pecking the comparison identical to the just-presented sample. Recently, a second type of matching-to-sample has been employed which utilizes only one key. Here a sample is presented and is followed by only one comparison. If that comparison is identical to the sample, pecks are reinforced; if it is not, pecks are not reinforced. Since the correct and incorrect comparisons are not presented simultaneously, but are presented successively, and only one after each sample, this procedure is sometimes referred to as a successive matching-to-sample task (see Wasserman, 1976). The matching-to-sample task is appropriate here because it has been found to be a relatively difficult task. For example, Honig and Wasserman (1981) compared pigeons' acquisition rates between a simple dis- 
crimination and a one-key symbolic matching-to-sample task. In the simple discrimination, the pigeons learned to discriminate between a red and a green light. In the matching task, responding to a red or green comparison depended on whether the sample was a set of vertical or horizontal lines. The results were clear: performance was higher and acquisition was faster for the simple discrimination. Honig and Wasserman concluded that the matching task was more difficult due to the amount of information required.

The present research sought to examine generalization gradients that occur after training on this type of one-key symbolic matching-to-sample task. More specifically, one group of pigeons was rewarded for responding to a black vertical line on white surround if the previous sample had been a blue light $(\mathrm{BV}+)$, but not if the sample had been a red light $(\mathrm{RV}-)$. Conversely, responding to a plain white light was reinforced after a red sample $(\mathrm{RW}+)$ but not after a blue sample (BW-). In a subsequent test phase, various line orientations appeared after red and blue samples and generalization gradients based on responding to the line's orientation were obtained. If both the color of the sample and the line orientation of the comparison exerted control, a decremental gradient should occur after blue and an incremental gradient should occur after red. Another group of pigeons was trained, but here the sample and comparison stimuli were reversed. Thus, the four training trials were V B,$+ \mathrm{VR}-, \mathrm{WR}+$, and WB-. During the test phase, the line was tilted away from vertical and responding to the red or blue comparison provided the data for the generalization gradients. If both color of the comparison and line orientation of the sample exerted control, then incremental and decremental gradients should emerge with red and blue comparisons, respectively.

\section{METHOD}

\section{Subjects}

Eight experimentally naive, adult, female White Carneaux pigeons were maintained at $80 \%$ of their free-feeding weights. Two of the 4 birds trained with line samples (described below) were dropped from the study; 1 bird died during magazine training and the 2 nd had failed to learn the discrimination after 146 sessions of training.

\section{Apparatus}

A standard three-key operant conditioning chamber was used (internal dimensions: $30.5 \times 35 \times 35 \mathrm{~cm}$ ). A Kodak slide projector located behind the center key presented the training and test stimuli. During the symbolic matching-to-sample task (described below), the stimuli were homogeneous red (R), blue (B), and white (W) colored keys or a black vertical line (approximately $2 \mathrm{~mm}$ thick) on a white key (V). When training involved a multiple schedule of reinforcement, the center key was illuminated by a plain red or blue light or the black vertical line appeared on the red or blue background. Durirg the generalization test five additional orientations of the black line on white background were presented (departures included: $+30^{\circ},+60^{\circ},-30^{\circ},-60^{\circ}$, and $\pm 90^{\circ}$ from vertical). Throughout, the side keys were covered with cardboard. A white houselight located above the center key provided general illumination of the chamber.

Presentation of stimuli and recording of responses were accom- plished by standard electromechanical equipment and a TRS-80 microcomputer connected to the chamber via a Med Associates Interface system. All equipment was located in an adjacent room.

\section{Procedure}

Each bird was trained to eat mixed grain from the food magazine and was autoshaped to peck a white center key (Brown \& Jenkins, 1968). Once keypecking was established, each bird received 50 trials of continuous reinforcement and was then exposed to the symbolic matching-to-sample task

At the beginning of each session of symbolic matching-to-sample training, the birds were placed in a dark chamber, the houselight was illuminated, and the intertrial interval (ITI) begun. The ITI had a minimum duration of $25 \mathrm{sec}$ but did not terminate within $5 \mathrm{sec}$ of a keypeck. Following the ITI, a sample appeared on the center key, and upon completion of a fixed interval of $5 \mathrm{sec}$ (FI $5 \mathrm{sec}$ ), the sample was removed, a .5-sec delay occurred, and a comparison stimulus appeared. When the comparison symbolically matched the sample, the comparison terminated after a FI $5 \mathrm{sec}$ was completed and the pigeon was given 3 -sec access to mixed grain. Mismatching comparisons were presented for $5 \mathrm{sec}$ and were automatically followed by a 3-sec blackout. After the trial outcome, the ITI began timing, unless it was the final trial of the session, in which case the houselight was turned off and the pigeon was returned to its home cage. For one session (50 trials), the sample and comparison was a white light and all trials ended with reinforcement.

Two groups of pigeons were trained on the symbolic matchingto-sample task. For the first group, the sample was either a $W$ or a $V$ stimulus followed by a $R$ or $B$ comparison. Responding to the $R$ comparison was reinforced if the sample was $W(W R+)$ but not when $V$ was the sample (VR-). Conversely, responding to a $B$ comparison was reinforced if $\mathrm{V}$ was the sample $(\mathrm{VB}+)$ but not when $\mathrm{W}$ preceded a $\mathrm{B}$ comparison (WB-). A second group of pigeons performed on the symbolic matching task, but here the sample and comparison stimuli were reversed. The colored lights served as samples, and the $\mathrm{W}$ and $\mathrm{V}$ stimuli were the comparisons. Thus, for pigeons trained with color samples, the four trial types were $\mathrm{RW}+$, $\mathrm{RV}-, \mathrm{BV}+$, and $\mathrm{BW}-$.

The pigeons that received line samples were trained and tested first. Sessions 1-26 each contained 30 presentations of the four training trials $(\mathrm{WR}+, \mathrm{VR}-, \mathrm{VB}+, \mathrm{WB}-)$. All trials were presented in mixed order. After 26 sessions, matching accuracy was near chance; consequently, the birds were removed from the symbolic matching task and were exposed to a multiple VI $30-\mathrm{sec}$ VI $30-\mathrm{sec}$ EXT EXT schedule of reinforcement. During Sessions 27-41 (80 trials per session), responding was reinforced when a black vertical line appeared on a blue background but not when it appeared on a red background. Conversely, responding to a solid red key was reinforced, but the plain blue key was associated with extinction. After 15 sessions of training under the multiple schedule, the birds were returned to the symbolic matching task, and during Sessions $42-161$ the probability that reinforcement followed matching comparisons was gradually reduced from 1.00 to .50 . Positive trials that did not end in reinforcement terminated automatically after 5 sec and a 3-sec blackout occurred.

Prior to each generalization test, each bird completed 80 warmup trials, which included 20 presentations of the four training trials; reinforcement was delivered on $50 \%$ of the positive trials. During the generalization test, the trial structure was identical to the warmup trials-ITI, sample, delay, and comparison durations were unchanged, except that the comparison stimulus terminated automatically after $5 \mathrm{sec}$ and a blackout occurred. The first generalization test included six presentations of the four training trials and six presentations of the generalization test samples (i.e., $+30 R$, $+60 \mathrm{R},-30 \mathrm{R},-60 \mathrm{R}$, and $\pm 90 \mathrm{R}$ ). On these trials, the line was tilted away from vertical and a red comparison appeared after the sample requirement was completed. The number of responses emitted to the red comparison after each line orientation provided the data for the generalization gradients. Prior to the second generali- 
zation test, the pigeons completed one normal session of symbolic matching-to-sample training. The second test was identical to the first, except that a blue comparison followed the five generalization test samples (i.e., $+30 \mathrm{~B},+60 \mathrm{~B},-30 \mathrm{~B},-60 \mathrm{~B}$, and $\pm 90 \mathrm{~B}$ ) and responses to the blue comparison provided the data.

A second group of pigeons was then trained on the symbolic matching task with color samples and $\mathrm{W}$ and $\mathrm{V}$ comparisons. Sessions 1-26 each contained 30 presentations of the four training trials $(\mathrm{RW}+, \mathrm{RV}-, \mathrm{BV}+, \mathrm{BW}-)$. After 26 sessions, the birds were removed from the matching task and exposed to the multiple schedule described in Phase 1. After 15 days of training on the multiple schedule, the pigeons were returned to the matching task. During Sessions 42-81, the probability that reinforcement followed matching comparisons was gradually reduced from 1.00 to .50 .

Session 82 began with 80 warm-up trials and ended with the first generalization test. As described above, the generalization test trials included six presentations of the four training trials $(R W+, R V-$, $\mathrm{BV}+, \mathrm{RV}-$ ) and six presentations of the five line orientations $(R+30, R+60, R-30, R-60, R \pm 90)$. During these trials, a red sample was presented, followed by a .5-sec delay and then one of five line orientations, which appeared as a comparison. Responses emitted to the comparison produced the data for the generalization gradients. On Session 82, a normal session of symbolic matchingto-sample training was completed; the next session contained the final generalization test. This second test was identical to the first, except that a blue sample preceded the five line orientations (i.e., $\mathrm{B}+30, \mathrm{~B}+60, \mathrm{~B}-30, \mathrm{~B}-60, \mathrm{~B} \pm 90$ ).

\section{RESULTS}

A discrimination ratio (DR) was used to evaluate performance during training. DRs were calculated by recording the number of responses to the comparison stimulus during its first $5 \mathrm{sec}$. The DR formula was $a /(a+b)$, where $a$ represents responses to the comparison when it symbolically matched the sample and $b$ represents responses when the comparison mismatched the sample. A DR of . 50 indicates that an equal number of responses occurred to the comparison stimuli regardless of the sample. A DR of 1.00 indicates perfect discrimination. Similar DRs were calculated when training involved the multiple VI VI EXT EXT schedule.

The left-hand portion of Figure 1 shows mean DRs for Pigeon 101 and Pigeon 102 during the symbolic matching-to-sample and multiple schedule discrimination tasks. Except for Block 5, which was based on six sessions, mean DRs were based on blocks of five sessions. Separate DRs were calculated when the vertical line (open circles) or white light (closed circles) was the sample. When training involved the multiple schedule, separate DRs were calculated for trials containing a vertical line on colored background (open circles) and for trials containing the solid red or blue key (closed circles).

Acquisition of the matching task was slow; DRs remained near chance for both pigeons after 26 sessions. Acquisition of the simple discrimination, however, was rapid; DRs increased to $.70-.90$ within 5 sessions, although when the birds were returned to the matching task, DRs fell to chance for 15 sessions. During the next 15 sessions, DRs increased to .80 for Pigeon 101 and to $.60-.80$ for Pigeon 102 throughout the last 105 sessions. Matching performance was relatively equivalent with $\mathrm{V}$ and $\mathrm{W}$ samples and remained stable as the percent of rewarded trials decreased.

The right-hand portion of Figure 1 shows the generalization gradients obtained when a red (open circles) or blue (closed circles) comparison followed the five line orientations. As can be seen, the generalization gradients
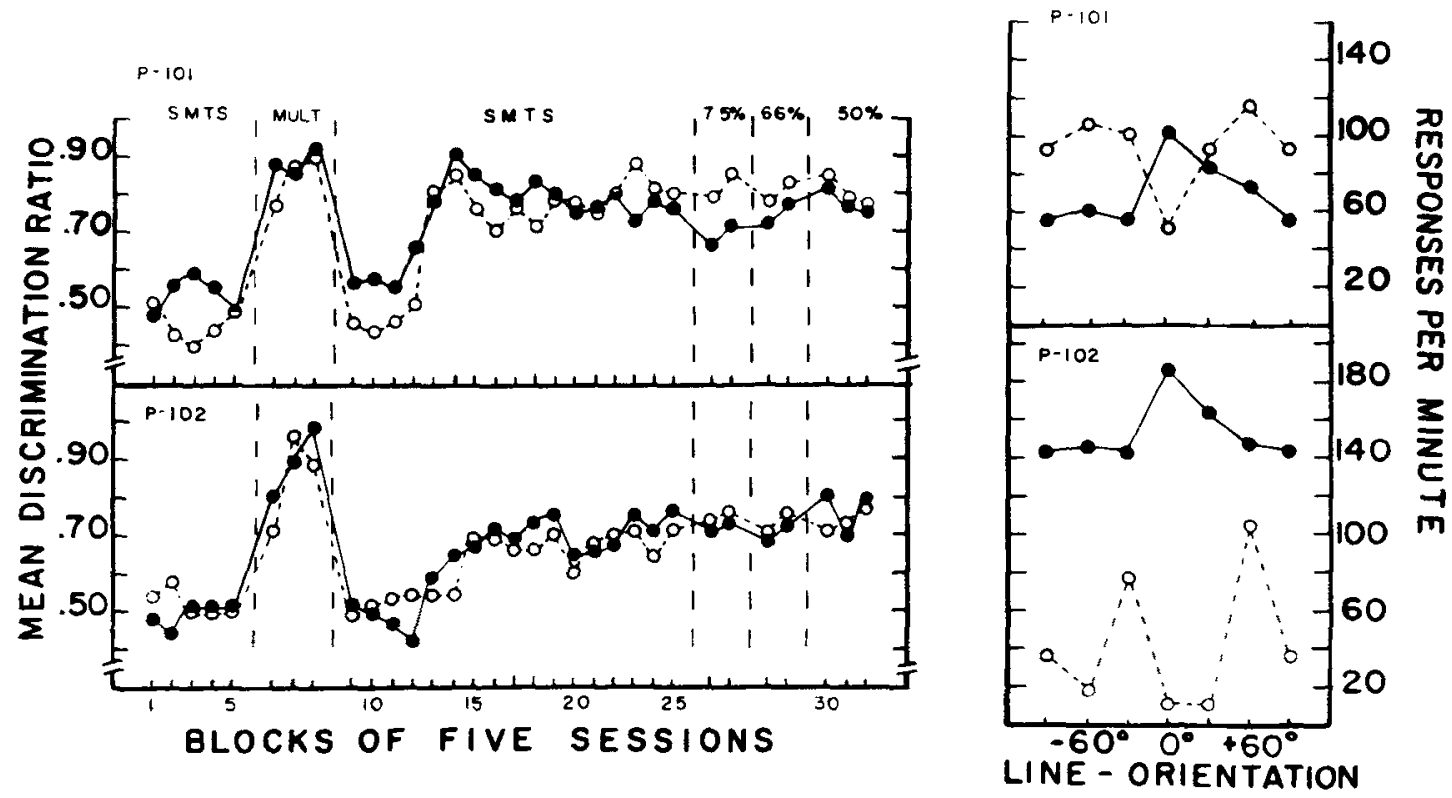

Figure 1. The left-hand portion shows the performance of pigeons trained with line samples during the symbolic matchingto-sample (SMTS) task and their accuracy during the multiple schedule (MULT). Open circles represent accuracy with vertical line samples, and closed circles depict performance after plain white samples. The right panel shows generalization gradients when a blue (closed circles) or red comparison (open circles) followed the various line orientation samples. 
peaked when a blue comparison followed a vertical line sample; as the line tilted away from vertical, responding decreased. Conversely, when a red comparison followed a vertical line sample, response rate was low but increased as the line tilted away from vertical. Although Pigeon 102 showed a more irregular incremental gradient, this bird still showed more responding after four of the five tilted lines than after the vertical lines.

Figure 2 shows performance for birds trained with color samples. Separate DRs were calculated when the comparison was a vertical line (open circles) or a plain white key (closed circles). Discrimination ratios during the multiple schedule were calculated as described earlier.

Acquisition of the matching task appeared slightly faster for pigeons trained with color samples. Three of the four birds showed DRs between .60 and .80 after 26 sessions, but DRs for Pigeon 201 remained at chance. Although all of the birds showed high DRs during the simple discrimination, this was followed by poor matching performance, except for Pigeon 202, which performed better during the matching task. During the last 40 sessions, all birds, except Pigeon 201, showed DRs that, at some point, exceeded .80; for Pigeon 201, DRs remained between .60 and .70 throughout.

The right-hand portion of Figure 2 shows the generalization gradients produced when the various line orientations followed a red (open circles) or blue (closed circles) sample. In every instance, when a vertical line followed a blue sample, the gradients peaked, and when the line's orientation tilted away from vertical, responding decreased.
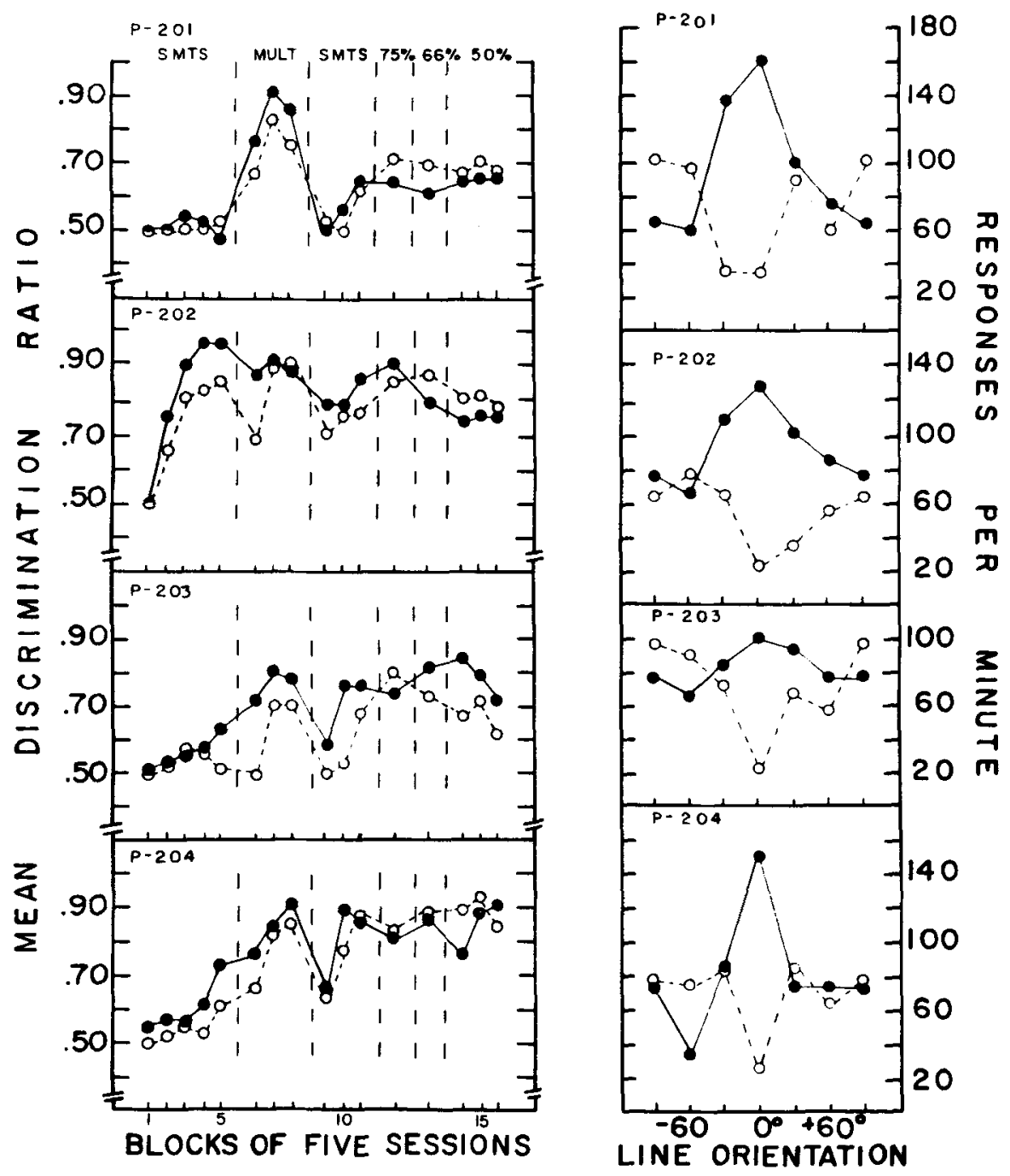

Figure 2. Symbolic matching-to-sample (SMTS) performance for pigeons trained with color samples. Open circles show performance with vertical line comparisons, and closed circles indicate accuracy with plain white comparisons. The right-hand portion shows generalization gradients when a red (open circles) or blue sample (closed circles) preceded the line orientation test comparisons. 
For all of the birds, responding was lowest when the red sample preceded the vertical comparison. As the line tilted away from vertical, U-shaped gradients emerged.

\section{DISCUSSION}

The major finding in the present experiment was that line orientation controlled responding after training on a one-key symbolic matching-to-sample task. When the vertical line appeared as the sample, testing along the line dimension produced incremental and decremental generalization gradients, depending on the color of the comparison. Conversely, when the vertical line served as the comparison, incremental and decremental gradients also emerged, but here the type of gradient depended on the color of the sample. Thus, both the color of the sample (comparison) and line orientation exerted control of behavior.

To some extent, the present experiment can be viewed as an extension of Richards's (1979) study, in which the colors and presence versus absence of a vertical line appeared simultaneously. In that study, decremental or incremental gradients were obtained along the line dimension depending on the color with which the line appeared. Although there are many methodological differences between the two studies (e.g., trial structure, schedule of reinforcement, duration of the stimuli and intertrial interval, etc.), two differences are especially relevant. First, the color cues were probably less salient in the present study, since they appeared on the key but did not also provide general illumination, as was the case in Richards's earlier study. In addition, for one group of subjects, the colors were absent during the comparison portion of the generalization test. It should be noted that Richards previously suggested that reducing the saliency of the colors might prevent the orientation of the line from gaining control over responding (cf. Boneau \& Honig, 1964). Second, for the other group, the various line orientations did not appear during the comparison portion of the generalization test, and it is responding during that portion that provides the data for the generalization gradients. The question was whether the orientation of the line would continue to exert control when the line was no longer present, and the present results showed clearly that line orientation did control responding.

The finding that line orientation controlled behavior is theoretically important in light of the fact that matchingto-sample is considered a relatively demanding task (see Honig \& Wasserman, 1981), involving both short- and long-term memory processes (Roitblat, 1980; Santi \& Roberts, 1985). It has been suggested (Boneau \& Honig, 1964; Sutherland \& Mackintosh, 1971) that when a task places a high demand on a subject's processing system, irrelevant features, such as a line's orientation, will not gain control of responding. The results obtained here, along with Richards's (1979) findings, challenge this notion and suggest that it has limited generality.
The finding that line orientation and color of the sample (or comparison) controlled responding is especially interesting because it has been suggested (Thomas, 1985) that on-key stimuli, such as lines and colors, are less likely to establish conditional control than are more diffuse stimuli (e.g., tones or houselight). More specifically, Thomas, McKelvie, Ranney, and Moye (1981) conducted a study in which pigeons were rewarded for pecking a $538-\mathrm{nm}$ light $(\mathrm{S}+)$, but not when the light was $576 \mathrm{~nm}$ $(\mathrm{S}-)$, and the context throughout was a houselight plus tone. After the pigeons mastered the $S+S-$ discrimination, the $S+$ and $S-$ stimuli were reversed. For example, pecking the 576-nm light was reinforced and the 538$\mathrm{nm}$ light was associated with extinction, but here the context was no houselight and white noise. On the next day, a generalization test was conducted along the color dimension in the presence of either context. The results were clear: the gradients peaked sharply at $538 \mathrm{~nm}$ in the presence of houselight plus tone and at $576 \mathrm{~nm}$ with no houselight plus white noise. Thus, after one reversal session contextual cues established conditional control over responding. However, Thomas (1985) described a similar study which employed on-key stimuli that failed to exert conditional control. In that study, responding to a vertical line on blue background was reinforced $(\mathrm{BV}+)$ but pecking to a horizontal line on blue background was not rewarded $(\mathrm{BH}-)$. On the next day, $\mathrm{S}+$ and $\mathrm{S}-$ were reversed, but now the lines appeared on a red background (e.g., RH + and RV-). Surprisingly, the subsequent generalization test failed to show conditional control by the color. Thus, Thomas showed that, with similar procedures, off-key stimuli established conditional control, whereas on-key stimuli did not. Thomas further suggested that on-key stimuli, which are directly responded to, are more likely to be treated as discriminative stimuli rather than conditional ones. Although the present results showed that on-key stimuli can establish conditional control, the data are consistent with Thomas's in that the matching task was learned with relative difficulty (cf. Richards, 1979; Thomas, 1985).

It is possible, however, to argue that the matching task used here was not sufficiently taxing to the pigeon's processing system, thus allowing line orientation to establish control. Although this seems unlikely, considering the difficulty at which the task was acquired, the matching procedure lends itself nicely to further manipulations which might permit more sensitive measures of stimulus control. For example, the delay between sample and comparison could be lengthened. With delays longer than the $.5 \mathrm{sec}$ used here, processing demand would presumably increase and it is likely that the subsequent generalization gradients would become flatter, yet DRs would ideally remain high. A further manipulation might involve increasing the number of stimuli contained in the sample. It is a common finding that matching is better when the sample contains only one element, and when an extra element is added, matching accuracy declines (Cox \& D'Amato, 1982; Lamb \& Riley, 1981; Richards \& Bowers, 1985; Santi, Grossi, \& 
Gibson, 1982). It has been suggested (Leith \& Maki, 1975; Maki \& Leith, 1973; Maki \& Leuin, 1972; Maki, Riley, \& Leith, 1976; Roberts \& Grant, 1978) that dual-element samples may require the subject to divide its attention among the separate elements, thereby taxing its attentional resources (for further discussion, see Riley \& Roitblat, 1978). If attentional capacity determines whether line orientation will exert control (see Sutherland \& Mackintosh, 1971), increasing the number of sample elements may prevent line orientation from establishing control and the subsequent generalization gradients should be relatively flat. It is also possible that the incremental gradient would become flatter sooner, since they tend to be more fragile (see Boneau \& Honig, 1964; Honig \& Beale, 1976; Jenkins, 1965). Research along these lines would seem fruitful in providing a better understanding of attentional capacity and its relationship with stimulus control.

\section{REFERENCES}

Boneau, C. A., \& Honig, W. K. (1964). Opposed generalization gradients based upon conditional discrimination training. Journal of $E x$ perimental Psychology, 68, 89-93.

Brown, P. L., \& Jenkins, H. H. (1968). Auto-shaping of the pigeon's key-peck. Journal of the Experimental Analysis of Behavior, 11, 1-8.

CARTER, D. E., \& Werner, T. J. (1978). Complex learning and information processing by pigeons: A critical analysis. Journal of the Experimental Analysis of Behavior, 29, 565-601.

Cox, J. K., \& D'Amato, M. R. (1982). Matching to compound samples by monkeys (Cebus appella): Shared attention or generalization decrement? Journal of Experimental Psychology: Animal Behavior Processes, 8, 209-225.

Farthing, G. W., Wagner, J. M., Gilmour, S., \& Waxman, H. M. (1977). Short-term memory and information processing in pigeons. Learning \& Motivation, 8, 520-532.

Gutrman, N., \& Kalish, H. I. (1956). Discriminability and stimulus generalization. Journal of Experimental Psychology, 51, 79-88.

Hearst, E., Besley, S., \& Farthing, G. W. (1970). Inhibition and the stimulus control of operant behavior. Journal of the Experimental Analysis of Behavior, 14, 373-409.

HoNIG, W. K. (1978). Studies of working memory in the pigeon. In S. H. Hulse, H. Fowler, \& W. K. Honig (Eds.), Cognitive processes in animal behavior. Hillsdale, NJ: Erlbaum.

HoNIG, W. K. (1984). Contributions of animal memory to the interpretation of animal learning. In H. L. Roitblat, T. G. Bever, \& H. S. Terrace (Eds.), Animal cognition. Hillsdale, NJ: Erlbaum.

HoNIG, W. K., \& BEALE, I. L. (1976). Stimulus duration as a measure of stimulus generalization. Journal of the Experimental Analysis of Behavior, 25, 209-217.

Honig, W. K., Boneau, C. A., Burstein, K. R., \& Pennypacker, H. S. (1963). Positive and negative generalization gradients obtained after equivalent training conditions. Journal of Comparative \& Physiological Psychology, 56, 111-116.

HoniG, W. K., \& URCuioli, P. J. (1981). The legacy of Guttman and Kalish (1956): 25 years of research on stimulus generalization. Journal of the Experimental Analysis of Behavior, 36, 405-445.

Honig, W. K., \& Wasserman, E. A. (1981). Performance of pigeons on delayed simple and conditional discriminations under equivalent training procedures. Learning \& Motivation, 12, 149-170.

JENKINS, H. M. (1965). Generalization gradients and the concept of inhibition. In D. I. Mostofsky (Ed.), Stimulus generalization. Stanford: Stanford University Press.

LAMB, M. R., \& RILEY, D. A. (1981). Effects of element arrangement on the processing of compound stimuli in pigeons (Columbia livia). Journal of Experimental Psychology: Animal Behavior Processes, 7, 45-48.

LeITH, C. R., \& MaKI, W. S., JR. (1975). Attentional shifts during matching-to-sample performance in pigeons. Animal Learning \& Behavior, 3, 85-89.

MAKI, W. S., JR., \& LEITH, C. R. (1973). Shared attention in pigeons. Journal of the Experimental Analysis of Behavior, 19, 345-349.

MAKI, W. S., JR., \& LEUIN, T. C. (1972). Information processing by pigeons. Science, 176, 535-536.

MAKI, W. S., JR., RiLEY, D. A., \& LeITH, C. R. (1976). The role of test stimuli in matching to compound samples by pigeons. Animal Learning \& Behavior, 4, 13-21.

Richards, R. W. (1979). Stimulus control following training on a conditional discrimination. Animal Learning \& Behavior, 7, 309-312.

Richards, R. W., \& Bowers, R. L. (1985). Dual-element effects in a one-key matching task with simultaneous and sequential elements. Psychological Record, 35, 575-582.

RileY, D. A., COOK, R. G., \& LAMB, M. R. (1981). A classification and analysis of short-term retention codes in pigeons. In G. H. Bower (Ed.), The psychology of learning and motivation: Advances in research and theory (Vol. 15). New York: Academic Press.

Riley, D. A., \& RoItblat, H. L. (1978). Selective attention and related cognitive processes in pigeons. In $S$. H. Hulse, H. Fowler, \& W. K. Honig (Eds.), Cognitive processes in animal behavior. Hillsdale, NJ: Erlbaum.

RILLING, M. (1977). Stimulus control and inhibitory processes. In W. K. Honig \& J. E. R. Staddon (Eds.), Handbook of operant behavior. Englewood Cliffs, NJ: Prentice-Hall.

RoBERTS, W. A., \& GRANT, D. S. (1978). Interaction of sample and comparison stimuli in delayed matching to sample with the pigeon. Journal of Experimental Psychology: Animal Behavior Processes, 4, 68-82.

Rortblat, H. L. (1980). Codes and coding processes in pigeon shortterm memory. Animal Learning \& Behavior, 8, 341-351.

Santi, A., Grossi, V., Gibson, M. (1982). Differences in matchingto-sample performance with element and compound sample stimuli in pigeons. Learning \& Motivation, 13, 240-256.

SANTI, A., \& RoberTs, W. A. (1985). Prospective representation: The effects of varied mapping of sample stimuli to comparison stimuli and differential trial outcomes on pigeons' working memory. Animal Learming \& Behavior, 13, 103-108.

Sutherland, N. S., \& MACKINTOSH, N. J. (1971). Mechanisms of animal discrimination learning. New York: Academic Press.

Terrace, H. S. (1966). Stimulus control. In W. K. Honig (Ed.), Operant behavior. New York: Appleton-Century-Crofts.

Thомаs, D. R. (1970). Stimulus selection, attention, and related matters. In J. H. Reynierse (Ed.), Current issues in animal leaming. Lincoln: University of Nebraska Press.

Thomas, D. R. (1985). Context stimulus control of operant responding in pigeons. In P. D. Balsam \& A. Tomie (Eds.), Context and learning. Hillsdale, NJ: Erlbaum.

Thomas, D. R., McKelvie, A. R., Ranney, M., \& Moye, T. B. (1981). Interference in pigeons' long-term memory viewed as a retrieval problem. Animal Learning \& Behavior, 9, 581-586.

Wasserman, E. A. (1976). Successive matching-to-sample in the pigeon. Behavior Research Methods \& Instrumentation, 8, 278-282.

(Manuscript received July 17,1985 ;

revision accepted for publication October 25,1985 .) 